\section{Hemosuccus pancreaticus after endoscopic ultrasound-guided fine needle aspiration of a pancreatic cyst}

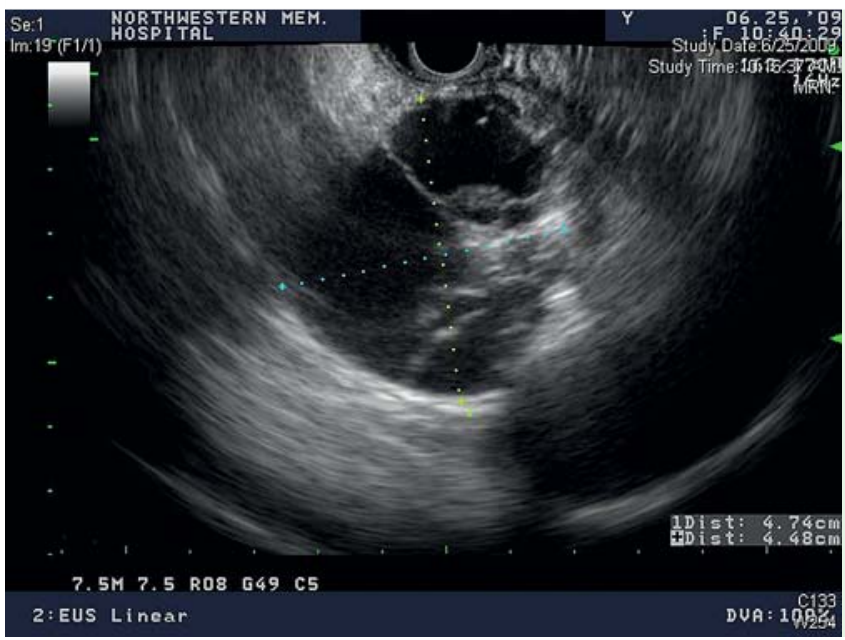

Fig. 1 Endoscopic ultrasound demonstrating a macrocystic pancreatic tail cyst with central calcification.

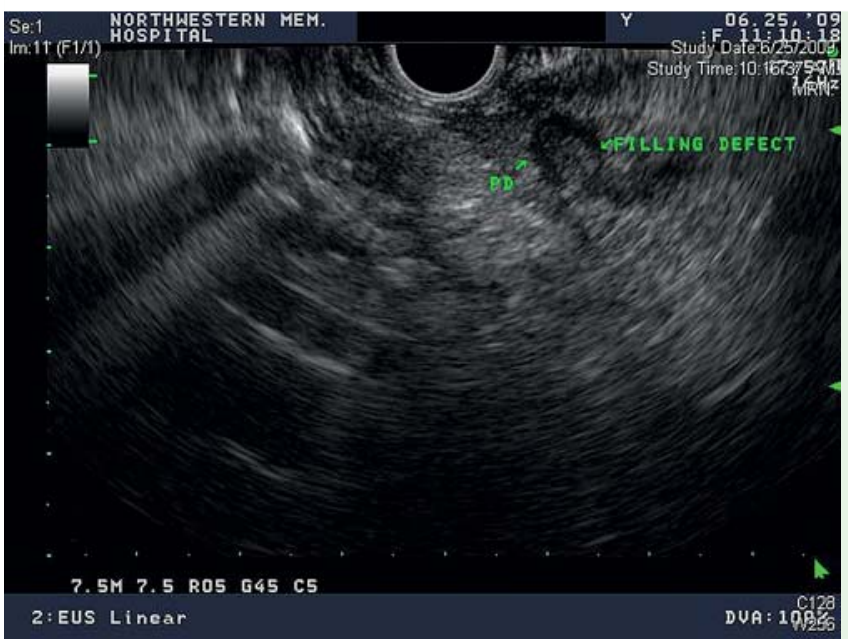

Fig. 3 Endoscopic ultrasound of the pancreatic duct near the ampulla demonstrating a hyperechoic filling defect consistent with blood. This was not seen prior to cyst aspiration.

A 71-year-old woman presented for endoscopic ultrasound (EUS) evaluation of a cystic lesion in the pancreas tail, which had been found on cross-sectional imaging during work-up of unintended weight loss. A $4.7 \times 4.5 \mathrm{~cm}$ anechoic, septated macrocystic lesion was seen in the pancreas tail with a central calcification $(\bullet$ Fig. 1). The remainder of the pancreas examination was normal. An avascular pathway was chosen and a 19-gauge needle was advanced into a large cystic component for fine needle aspiration (FNA). A frankly bloody aspirate was seen. Repeat EUS-FNA of a separate component of the cyst yielded slightly viscous, clear, nonbloody fluid, which was sent for analysis. The echoendoscope was then readvanced into the second portion of duodenum, demonstrating fresh blood emanating adenoma.

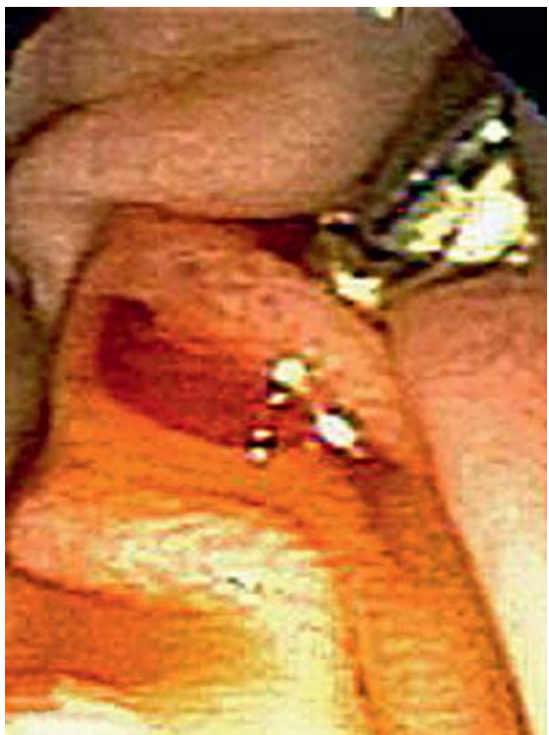

Fig. 2 A biopsy forceps was used to uncover the ampulla, with blood emanating from the papillary orifice.

case conservative management resulted in complete resolution.

Endoscopy_UCTN_Code_CPL_1AL_2AF

\section{R. N. Keswani}

Division of Gastroenterology, Department of Medicine, Northwestern University

Feinberg School of Medicine, Chicago, Illinois, USA

\section{References}

1 Al-Haddad M, Wallace MB, Woodward TA et $a l$. The safety of fine-needle aspiration guided by endoscopic ultrasound: a prospective study. Endoscopy 2008; 40: 204-208

2 Singh P, Gelrud A, Schmulewitz N, Chauhan S. Hemosuccus pancreaticus after EUS-FNA of pancreatic cyst (with video). Gastrointest Endosc 2008; 67: 543

3 Bournet B, Migueres I, Delacroix M et al. Early morbidity of endoscopic ultrasound: 13 years' experience at a referral center. Endoscopy 2006; 38: 349-354

\section{Bibliography}

DOI $10.1055 / \mathrm{s}-0029-1243869$

Endoscopy 2010; 42: E79

(C) Georg Thieme Verlag KG Stuttgart · New York ISSN 0013-726X did not need further therapy. Histologic examination of the surgically resected cyst demonstrated a benign serous cyst-

EUS-FNA is a procedure with a well-described low complication rate [1]. Intracystic bleeding after EUS-FNA can occur, however, and rarely may result in hemosuccus pancreaticus [2,3]. A 19-gauge FNA needle was used for cyst aspiration in the present case, which may possibly contribute to this complication. In this

\section{Corresponding author}

\section{R. N. Keswani, MD}

Division of Gastroenterology,

Department of Medicine, Northwestern University Feinberg School of Medicine

676 N. St. Clair Street

14th Floor

Chicago

IL 60611

USA

raj-keswani@northwestern.edu 